\title{
Article
}

\section{Exploring the therapeutic relationship in nursing theory and practice}

Wright, Karen Margaret

Available at http://clok.uclan.ac.uk/37860/

Wright, Karen Margaret ORCID: 0000-0003-0693-7294 (2021) Exploring the therapeutic relationship in nursing theory and practice. Mental Health Practice . ISSN 1465-8720

It is advisable to refer to the publisher's version if you intend to cite from the work. http://dx.doi.org/10.7748/mhp.2021.e1561

For more information about UCLan's research in this area go to http://www.uclan.ac.uk/researchgroups/ and search for < name of research Group>.

For information about Research generally at UCLan please go to http://www.uclan.ac.uk/research/

All outputs in CLoK are protected by Intellectual Property Rights law, including Copyright law. Copyright, IPR and Moral Rights for the works on this site are retained by the individual authors and/or other copyright owners. Terms and conditions for use of this material are defined in the policies page.

\section{CLoK}

Central Lancashire online Knowledge www.clok.uclan.ac.uk

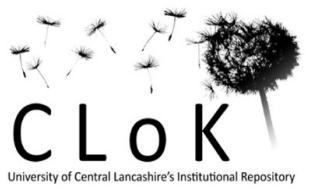




\section{Mental Health Practice: evidence \& practice | CPD}

\section{Why you should read this article:}

- To learn more about the therapeutic relationship and its central role in mental health nursing practice

- To find out how you can use yourself as an instrument of care in the therapeutic relationship

- To count towards revalidation as part of your 35 hours of CPD, or you may wish to write a reflective account (UK readers)

- To contribute towards your professional development and local registration renewal requirements (non-UK readers)

\section{Title: The therapeutic relationship in nursing theory and practice}

\section{Karen M. Wright}

\section{Citation}

Wright KM (2021) The therapeutic relationship in nursing theory and practice. Mental Health Practice. doi: 10.7748/mhp.2021.e1561

\section{Peer review}

This article has been subject to external double-blind peer review and has been checked for plagiarism using automated software

\section{Correspondence}

kmwright1@uclan.ac.uk

\section{Conflict of interest \\ None declared}

\section{Accepted}

12 April 2021

\section{Abstract}

The therapeutic relationship is widely seen as central to nursing practice, yet it is so familiar that it is easily taken for granted. However, like any relationship, it cannot be assumed, and to be therapeutic it requires investment from both parties. Mental health nurses need to know how to develop a therapeutic relationship that is helpful and acceptable to service users. This article outlines the theoretical background and fundamental components of the therapeutic relationship. It discusses the importance of self-awareness, reflection and professionalism, as well as how mental health nurses use themselves as an instrument of care and become a catalyst in the service user's journey to recovery. It describes the essential qualities and skills required to develop optimal therapeutic relationships with service users and introduces a new mnemonic which encapsulates some of these qualities and skills. 


\section{Author details}

Karen M. Wright, Professor of Nursing, Faculty of Health and Care, University of Central Lancashire, Preston, England

\section{Keywords}

communication, interpersonal skills, mental health, mental health therapies, nurse-patient relations, nursing models and theories, professional, professional issues, therapeutic relationships

\section{Aims and intended learning outcomes}

The aim of this article is to provide an overview of the therapeutic relationship in nursing theory and practice, highlighting its importance in mental health nursing practice and the essential qualities and skills it requires from mental health nurses. After reading this article and completing the time out activities you should be able to:

1. Explain the concept of therapeutic relationship, its theoretical background and the contemporary thinking about it.

2. Recognise how the therapeutic relationship is linked to a person-centred approach.

3. Understand how mental health nurses use themselves as an instrument of care in the therapeutic relationship.

4. Describe some of the essential qualities and skills required to develop optimal therapeutic relationships with service users.

\section{Introduction}

Mental health nursing, more than any other field of nursing, relies on how we, as mental health nurses connect with those who seek support and care on their journey to recovery - that is, on the development of a therapeutic relationship. The term 'therapeutic relationship' is found in most care plans and nursing textbooks, although other terms with the same meaning are used as well, such as 'working alliance', 'nursepatient relationship' and 'helping alliance'. The therapeutic relationship is the 'backbone of nursing practice' (Moreno-Poyato and Rodríguez-Nogueira 2020), yet it is so familiar that it is easily taken for granted. The very experience of being in the presence of a mental health nurse who connects with the service user in such a way that they feel valued and heard is precious in itself, as it creates the right environment for therapeutic interventions to occur. Yalom went so far to say that a good therapeutic relationship was even healing in its own right (Yalom 1980), as the relationship is the conduit for the therapy. However, like any relationship, it cannot be assumed, and to be therapeutic it requires investment from both parties.

This article considers how we can recognise our part in the development of a therapeutic relationship that is a conscious and deliberate attempt to create a safe space where we can become a catalyst for service users' recovery. The article outlines the theoretical background and fundamental components of the therapeutic relationship. It describes the essential qualities and skills required to develop optimal therapeutic relationships with service users and introduces a new mnemonic, proposed by the author (Wright 2021) which encapsulates some of these qualities and skills.

\section{Theoretical background}

Freud is considered to have established the idea that the relationship between patient and therapist, and is accredited with being to first to use it, defining it as a 'friendly affectionate feeling, which was the "unobjectionable positive transference" with psychoanalysis (Freud, 1912: 105) although the concept has moved on significantly within other professions, including nursing, since then. He also recognised that 
perspectives can be distorted within the therapeutic relationship because of unconscious and emotional factors (Breuer and Freud 1885, Freud 1936).

\section{Peplau's and Bordin's models}

Hildegard Peplau (1909-1999), an American nurse and nursing theorist [was influenced by psychodynamic theory (Freud 1936) ] In her 'nurse-patient relationship' model, Peplau emphasised the unique and individual experience of the person and described different roles nurses play in the nurse-patient relationship, including the 'mother-surrogate', the 'technician', the 'manager', the 'socialising agent', the 'health teacher' and the 'counsellor or psychotherapist' (Peplau 1952, 1988).

Later, Peplau developed her 'interpersonal relations model', which comprises four phases: 'orientation', 'identification', 'exploitation' and 'resolution' (Peplau 1988). These phases are experienced sequentially as the therapeutic relationship develops. The 'orientation phase' is the introductory phase when the service user and nurse first meet, and each determines their part in the relationship.

According to Peplau, this is when the connection is made, and trust is established. However, trust is not immediate; first you must develop a rapport, which requires considerable skill (McCormack and McCance 2017

Next, 'identification' refers to the identification of the service user's needs, and how to address these by establishing a care plan and determining who needs to be involved in their care. At this stage the nurse needs to create a sense of hope and optimism thus enabling the service user to recognise the potential for recovery. 'Exploitation' seems like an unusual term to use in a helping relationship, as it is used to refer to using resources available to you to problem solve and build independence. Finally, the 'resolution' phase is evaluative, it is when goals are revisited and prepares the service user to break the bond with the with the nurse in readiness for discharge

\section{Time Out 1}

Reflect on a therapeutic relationship you developed with a service user which led to their recovery. How did you establish, build on and sustain a bond with that person? How did you work with them to identify and agree the goal of the therapeutic relationship? How did you negotiate the tasks required to reach that goal?

While Peplau $(1952,1988)$ focused on the different roles nurses play in the nurse-patient relationship, Bordin $(1979,1994)$ focused on three interdependent components of the 'working alliance' (another term for therapeutic relationship):

- Goal - Identifying and agreeing a goal.

- Task - Negotiating the tasks required to reach that goal.

- Bond - Sustaining a bond as the relationship progresses.

In Bordin's model, the bond refers to the creation of the secure attachment first described by Bowlby (1980) and more recently by Skourteli and Lennie (2011). Bordin's model may appear simplistic, but Bordin's model integrates the fact that relationships do not necessarily travel in straight lines. They are constantly renegotiated as we build rapport, establish our trustworthiness and try to understand the service user's narrative. Additionally, the nurse and service user will not always see eye to eye, so the process of working together to negotiate an acceptable care plan may produce a tearing of the relationship, which is sometimes referred to as a 'rupture' . Bordin $(1979,1994)$ believes that it is the subsequent healing of the relationship that enables change. 


\section{Contemporary thinking}

Since Freud, Peplau and Bordin, many others have attempted to define the therapeutic relationship - for example, Clarkson (2003) and Morgan (1996) . Contemporary thinking about mental health nursing challenges the concept of the nurse as 'problem solver', as described by Morgan (1996), and moves us to a position where the therapeutic relationship is founded on collaboration, partnership and mutuality, and where there is shared ownership of care planning (McKeown et al 2017). The therapeutic relationship has been enhanced by the application of evidenced-based practice and shared decision-making in clinical practice (Barker and Williams 2018, Moreno-Poyato and Rodríguez-Nogueira 2020).

It could be said that engagement is the precursor of the therapeutic relationship, since a relationship cannot develop until a connection has been made. Ryan and Morgan (2004) described engagement as 'a separate and distinct function, the foundation of all aspects of the helping process. It is an attempt to build an ongoing constructive partnership and will most usually be facilitated by a series of unstructured, informal and shared encounters, that take place at the beginning of the process of relationship building. It is a therapeutic activity within its own right, needing to be positively monitored and sustained throughout the duration of the helping process' Ryan and Morgan's (2004) reference to a 'constructive partnership' is worth noting, since in contemporary nursing practice we aim to build a therapeutic relationship based on equality, respect and co-production of care, (Rippon and Hopkins 2015).

\section{Time Out 2}

Think about the qualities and skills you use when you meet a service user for the first time. What do you do and/or say to make them to feel safe? To gain their trust? To prompt to engage in the therapeutic relationship?

\section{Being one's own instrument of care}

In the therapeutic relationship, we are our own instrument of care and we use ourselves in our practice, thus creating person-centred care on a human level (Wright, 2010) [Rowan and Jacobs (2002) described the ability to switch oneself on and off at will as a 'therapeutic instrument'. This resonates with Barker and William's (2018) view of compassionate communication, which requires awareness of the self as well as the needs of the other person.

Benner (1984) described the skills nurses need for increasing their self-awareness and reflecting on their practice Along with Schön (1983), Benner (1984) suggested that nurses' actions are often intuitive rather than considered. This led Schön (1983) and Benner (1984) to recommend that nurses reflect more on their practice, the rationale for their decisions, their effect on others and the possibility of doing things differently to achieve better outcomes. The inference is that nurses who are not self-aware cannot recognise the effect they have on others and may therefore develop an unprofessional or unhelpful therapeutic relationship with patients.

Freshwater (2002) reinforced that message, arguing that when a person is unwell, they see themselves differently and that it is the responsibility of the nurse to assist the person back to a '(re)emergence of the self'. Again, that can only happen if the nurse is self-aware and holds an optimistic view of the person's potential to attain recovery. This humanistic approach resonates with the work of Rogers (1961), who exposed how the therapist needs to take a person-centred approach and view the person with 'unconditional positive regard'.

\section{Measuring the therapeutic relationship}

There are several scales used to measure the therapeutic relationship. To a large extent, they are used in psychotherapy practice, not in mental health nursing practice - which is why they use the term 'therapist', 
for example. Probably the best-known of these scales is the 12-item Working Alliance Inventory (WAI) (Horvath and Greenberg, 1994). The 12 WAl items are rated on a Likert-type scale and assess the three components of Bordin's $(1979,1994)$ model (Hatcher and Gillaspy 2006

- Goal: agreement between patient and therapist on the goal of therapy.

- Task: agreement between patient and therapist about how the therapy will address the problems the patient brings to treatment.

- Bond: quality of the interpersonal bond between patient and therapist.

Kim et al (2001) created the Kim Alliance Scale to measure the effectiveness of the 'alliance' (another term for therapeutic relationship), which has four components: 'collaboration', 'communication', 'integration' and 'empowerment'. Empowerment refers to the patient's ability to act independently and exercise selfdetermination, but the term is controversial, since it implies that the therapist holds power that they gift to the patient (Wright, 2015)

While not a measure of the therapeutic relationship as such, the Interpersonal Reactivity Index (IRI) created by Davis (1983) measures empathy through factors identified as being present in empathy Davis (1983) defines empathy as the "reactions of one individual to the observed experiences of another" and his IRI is a Likert scale with 28 -items divided into are 4 subscales:

- Perspective Taking - the tendency to spontaneously adopt the psychological point of view of others Fantasy - taps respondents' tendencies to transpose themselves imaginatively into the feelings and actions of fictitious characters in books, movies, and plays

- Empathic Concern - assesses "other-oriented" feelings of sympathy and concern for unfortunate others

- Personal Distress - measures "self-oriented" feelings of personal anxiety and unease in tense interpersonal settings

(Davis , 1983)

\section{Time Out 3}

Reflect on the opening of a recent therapeutic relationship with a service user. Did you find an optimal balance between authenticity and professional distance? Between showing empathy and demonstrating clinical expertise? To assist in establishing the relationship, did you use techniques such as:

Active listening to demonstrate that you acknowledge and respect the service user's concerns?

Paraphrasing and summarising to explore in more depth their circumstances, experiences and concerns?

\section{Essential qualities and skills}

If we accept that the therapeutic relationship is fundamental to person-centred care, we need to recognise what essential qualities and skills are required to develop a therapeutic relationship that is helpful and acceptable. Table 1 outlines a new mnemonic which encapsulates some of these qualities and skills. The mnemonic spells the word ATTACH, which resonates with Bordin's focus on the bond. 


\begin{tabular}{|c|c|c|}
\hline A & Authentic & $\begin{array}{l}\text { Being authentic with service users is crucial, since we are our own } \\
\text { instrument of care and we use ourselves in our practice }\end{array}$ \\
\hline $\mathrm{T}$ & Trustworthy & $\begin{array}{l}\text { Being a reliable and well-informed professional incites service } \\
\text { users to trust you, your judgement and your practice }\end{array}$ \\
\hline $\mathrm{T}$ & Time-maker & $\begin{array}{l}\text { Making time to be with service users makes them feel cared for and } \\
\text { listened to and enables us to discuss the timeframe of care, } \\
\text { including the ending of the therapeutic relationship }\end{array}$ \\
\hline A & Approachable & $\begin{array}{l}\text { Being approachable and visible, being a good listener and } \\
\text { providing empathic responses is paramount }\end{array}$ \\
\hline C & $\begin{array}{l}\text { Consistent } \\
\text { communicator }\end{array}$ & $\begin{array}{l}\text { Communication is crucial and we also need to provide a consistent } \\
\text { message, work as part of a team within recognised models of } \\
\text { practice and meet the requirements of the Nursing and Midwifery } \\
\text { Council }\end{array}$ \\
\hline $\mathrm{H}$ & Honest & $\begin{array}{l}\text { Honesty is a fundamental value of the nursing profession and } \\
\text { enables us to have open and realistic conversations with service } \\
\text { users }\end{array}$ \\
\hline
\end{tabular}

\section{Being authentic}

Being authentic with service users is crucial, since we are our own instrument of care and use ourselves in our practice. Authenticity is characterised by trustworthiness, honesty, reliability, openness, compassion and genuine hope for service users' recovery. However, authenticity needs to be underpinned by evidencedbased practice (Bugental1987), Humanness, compassion, reliability, hope and optimism enable us to be authentic, while evidenced-based practice enables us to provide care from an informed position. The combination of authenticity and evidence-based practice therefore enables us to be seen as dependable and reliable professionals.

Daniel (1998) identified vulnerability as the key to authenticity, explaining that 'vulnerability gives nurses the opportunity to be authentic'. Daniel urged us need to recognise our own vulnerability so that we can recognise it in others, enter 'mutual vulnerability' and create a relationship which acknowledges our shared humanity. When we are authentic, we become believable, as long as we remain focused on each individual service user. As explained by Christiansen (2009), 'it is not enough to "be yourself" when caring for patients; one has to be able to use one's personality in a flexible way that is adapted to each individual patient and each situation' It is possible - and recommended - to be authentic without crossing professional boundaries. Optimal professional boundaries create a safe space in which trust can develop and the Nursing and Midwifery Council (NMC) expects its registrants to 'stay objective and have clear professional boundaries at all times with people in [their] care' (NMC 2018a).

\section{Being trustworthy}

Being a reliable and well-informed professional incites service users to trust you, your judgement and your practice. Trust is fundamental to the therapeutic relationship (Clarkson 2003, Forchuk 1994, Peplau 1952, 1988, Travelbee 1971, Wright and McKeown 2018), since confidential disclosure is impossible without trust (Bond 1994). It would be easy to fall into the trap of believing that if we are compassionate and caring, service users will necessarily trust us. We need to recognise that certain features of service users' experience may get in the way of them trusting us - for example, paranoia and suspicion, such as seen in psychosis; adverse childhood events; or fear of the treatment itself, such as seen in anorexia nervosa. Whether service users feel able to trust us also depends on their past and current relationships, including with mental health services.? . We need to support service users to feel safe and confident in their treatment, as many feel misunderstood and scared (Wright and Hacking, 2012) 
Dickinson (2011) suggested that we are constantly striving to achieve authenticity and that one of the important factors in this endeavour is our capacity to trust others. Using ourselves in our practice means using fundamental human qualities such as trustworthiness, honesty and openness (Peterson and Seligman 2004, NMC 2018a). However, what services users primarily trust us to do is to offer evidence-based care, so using ourselves in our practice is not sufficient to gain their trust. This also requires us to use evidence-based practice. Moreno-Poyato et al (2021) conducted a participatory action study whereby they reserved therapeutic space, and also conducted reflective post incident analysis in an attempt to improve the therapeutic relationship among mental health nurses. They found that nurses who demonstrated optimal knowledge of evidence-based practice and professional attitudes achieved better shared decision-making with service users

\section{Time Out 4}

Identify the barriers to optimal therapeutic relationship that exist in your practice setting and discuss them with your colleagues and/or with your clinical supervisor to determine whether and how they can be overcome

\section{Being a time-maker}

Making time to be with service users makes them feel cared for and listened to and enables us to discuss the timeframe of care, including the ending of the therapeutic relationship Finding time to be with service users can seem an impossible task, considering the many other priorities that require our attention. Taking the right approach in the time available to us and make the most valuable and realistic use of that time is paramount. Being aware of what may impede the therapeutic relationship, such as a lack of time, is the first step to overcome barriers. According to Harris and Panozzo (2019), 'if the nurse is not aware of how he or she responds to time pressure, frustration or lack of clarity of practice policy and address this, there is a risk that the patient may perceive the nurse's actions as lacking in care, presence or involvement'

There is such emphasis on developing a therapeutic relationship that it is easy to forget that its ultimate goal is for service users to reach a position of independence where separation from you and the service is possible and safe discharge can occur. This stage of the therapeutic relationship is referred to as the 'resolution phase' by Peplau (1952) , and the 'termination phase' by Mann (1973) and Macneil et al (2010). We need to ensure that, during the course of the therapeutic relationship, we make frequent reference to the goals of therapy, in preparation for discharge, to prevent service users feeling abandoned or betrayed (Ryle 1995). If done well and within professional boundaries, the resolution phase will occur incrementally, as the goals of treatment are being met, and will enable the person to feel safe and secure about the impending separation.

\section{Time Out 5}

As part of the celebrations for its 100th anniversary, the Royal College of Nursing asked healthcare support workers to share their expertise and contribution to patient care. This resulted in '100 top tips', many of which relate to communication and empathy. Go to rcn.org.uk/centenary/projects/100-top-tips/communication-and-empathy to read these 'top tips'. Are any of them useful to consider in relation to the therapeutic relationship? What are your 'top tips' for developing optimal therapeutic relationships? 


\section{Being approachable}

Being approachable is generally considered to refer to being friendly and kind; for mental health nurses it is much more. It is about being accessible and visible, being a good listener and providing empathic responses is paramount. Approachability is created by demonstrating compassion, kindness, but it is more than that, as mental health nurses are often seen as being in positions of authority and so being 'approachable' enables co-production and partnership. It means being accessible and open to hearing other people's perspectives. Very few studies have considered this, and none referring to mental health nursing, but a study by PetronioCoia et al (2020) researched approachability and children's nurses and concluded that it was the responsibility of the nurse to ensure that those in their care were heard, understood and respected with 'unprecedented dignity'; a position that is clearly transferable to mental health nursing.

\section{Being a consistent communicator}

Communication is crucial and we also need to provide a consistent message, work as part of a team within recognised models of practice, and meet the requirements of the NMC (2018a, 2018b). In its standards of proficiency for registered nurses, the NMC clearly states that 'effective communication is central to the provision of safe and compassionate person-centred care. Registered nurses in all fields of nursing practice must be able to demonstrate the ability to communicate and manage relationships with people of all ages with a range of mental, physical, cognitive and behavioural health challenges' (NMC 2018b). The standards of proficiency for registered nurses outline a wide range of communication and relationship management skills that nurses need to be able to demonstrate (NMC 2018b). Our service users rely upon consistency of communication across members of a team, as inconsistency causes confusion and mistrust, this is particularly important in older people's service, were forgetfulness may cause a service user the ask the same question repeatedly, and where the quality of the communication has a profound effect on the relationship, according to Mccarthy, (2010) who says that :

"Communication is the food of relationships. Good communication is nourishing, delightful and memorable. It creates intimacy, enriches us and we become better people. Poor communication is like bad foodpoisonous and harmful" (McCarthy,B 2010.

\section{Being honest}

Honesty is a fundamental value of the nursing profession and enables us to have open and realistic conversations with service users. The NMC states that, to uphold the reputation of the nursing profession, we must 'act with honesty and integrity at all times' (NMC 2018a). Honesty is required in many aspects of the therapeutic relationship. For example, honesty means being open and realistic about treatment options and possible outcomes; being clear about how service users' information may be shared with others; and being honest with ourselves in the evaluation of our own practice (Oliver 2017, Price 2019). Being honest and open requires sensitivity and the ability to perceive how service users are receiving messages.

It can be tempting to attempt to make the therapeutic relationship more honest and open by using selfdisclosure - that is, the sharing of one's own experiences with service users - which can create a sense of shared experience and identification. There are examples where a degree of self-disclosure has been shown to enable nurses to connect with service users because they share certain interests (Wright and Jones 2012) or simply because they talk about 'normal stuff' (Jones and Wright 2017). Unhjem et al (2018) found that the overarching reason why nurses shared their own experiences was because it felt natural to respond to service users' questions. According to Unhjem et al (2018), the outcomes obtained from self-disclosure vary and are not consistent. Self-disclosure can create confusion, where 'friendliness' is mistaken for 'being a friend', thereby blurring professional boundaries and creating tensions (Hem and Heggen 2003). If you find yourself sharing details of your own experience with a service user, stop and think whether it is of benefit in 
your therapeutic relationship with the person and remember that they must always be the focus of the interaction.

\section{Conclusion}

Developing optimal therapeutic relationships is crucial at all levels of mental health nursing practice; even healing in its own right (Yalom 1980), although often difficult to establish in contemporary practice The therapeutic relationship places nurses in a prime position to become a catalyst for change and work with service users towards their recovery. When engaging in therapeutic relationships, mental health nurses need to demonstrate self-awareness, empathy and professionalism, and back up their practice with evidencebased approaches. The mnemonic ATTACH - whereby nurses need to be 'authentic', 'trustworthy', 'timemakers', 'approachable', 'consistent communicators' and 'honest' - encapsulates some of the essential qualities and skills required to develop optimal therapeutic relationships with service users.

\section{Time out 6}

Consider how developing optimal therapeutic relationships relates to The Code: Professional Standards of Practice and Behaviour for Nurses, Midwives and Nursing Associates (NMC 2018a) or for non-UK readers the requirements of your regulatory body

\section{Time out 7}

Now that you have completed the article, reflect on your practice in this area and consider writing a reflective account: rcni.com/reflective-account

\section{References}

Barker and Williams (2018) Compassionate communication in mental health care In Wright KM, McKeown M (Eds) Essentials of Mental Health Nursing. SAGE, London, pp297-313.

Benner P (1984) From Novice to Expert: Excellence and Power in Clinical Nursing Practice. Addison-Wesley, Menlo Park CA.

Bond T (1994) Standards and Ethics for Counselling in Action. SAGE, London.

Bordin E (1979) The generalizability of the psychoanalytic concept of the working alliance. Psychotherapy: Theory, Research, and Practice. 16, 252-260. doi: 10.1037/h0085885

Bordin E (1994) Theory and research on the therapeutic working alliance: New directions. In Horvath AO, Greenberg LS (Eds) The Working Alliance: Theory, Research, and Practice. Wiley, New York NY, Ch 1: pp13-38

Bowlby J (1980) Attachment and Loss Volume 3. Loss, Sadness and Depression. Hogarth Press, London.

Breuer J, Freud S (1885) Studies on hysteria.: Strachey, J. (1955). The Standard Edition of the Complete Psychological Works of Sigmund Freud, Volume II (1893-1895): Studies on Hysteria. The Standard Edition of the Complete Psychological Works of Sigmund Freud, Volume II (1893-1895): Studies on Hysteria, i-vi. The Hogarth Press and the Institute of Psycho-Analysis, London.

Bugental, J. (1987) The Art of the Psychotherapist New York: W.W. Norton

Christiansen B (2009) Cultivating authentic concern: exploring how Norwegian students learn this key nursing skill. Journal of Nursing Education, 48, 8, 429-433. doi: 10.3928/01484834-20090518-03 
Clarkson P (2003) The Therapeutic Relationship. Second edition. Whurr, London.

Daniel LE (1998) Vulnerability as a key to authenticity. Image - the Journal of Nursing Scholarship. 30, 2, 191192. doi: 10.1111/j.1547-5069.1998.tb01279.x

Davis MH (1983) Measuring individual differences in empthy: Evidence for a mult-dimensional approach. Journal of Personality and Social Psychology 44, 1, 113-126.

Dickinson, B. J. (2011) The Role of authenticity in relationship marketing. Journal of Management and Marketing Research, 8 1-12Forchuk C (1994) The orientation phase of the nurse-client relationship: testing Peplau's theory. Journal of Advanced Nursing. 20, 3, 532-537. doi: 10.1111/j.1365-2648.1994.tb02392.x

Freshwater D (2002) The Therapeutic Use of Self in Nursing. $n$ Therapeutic Nursing: Improving Patient Care through Self-Awareness and Reflection SAGE, London, pp1-16.

Freud, S. (1912), Recommendations to physicians practicing psycho-analysis. Standard Edition, 12: 109-120. London: Hogarth Press, 1958.

Freud S (1936) The Problem of Anxiety [Translated by Bunker HA (2013)]. W Norton \& Co., New York NY.

Harris B, Panozzo G (2019) Barriers to recovery-focused care within therapeutic relationships in nursing: attitudes and perceptions. International Journal of Mental Health Nursing. 28, 5, 1220-1227. doi:

10.1111/inm.12611

Hem MH, Heggen K (2003) Being professional and being human: one nurse's relationship with a psychiatric patient. Journal of Advanced Nursing. 43, 1, 101-108. doi: 10.1046/j.1365-2648.2003.02677.x.

Hatcher, R. L.,Gillaspy, J. A. (2006). Development and validation of a revised short version of the Working Alliance Inventory. Psychotherapy Research, 16(1), 12-25.

Jones ES, Wright KM (2017) "They're really PD today": an exploration of mental health nursing students' perceptions of developing a therapeutic relationship with patients with a diagnosis of antisocial personality disorder. International Journal of Offender Therapy and Comparative Criminology. 61, 5, 526-543. doi: 10.1177/0306624X15594838

Kim SC, Boren D, Soren SL (2001) The Kim Alliance Scale: development and preliminary testing. Clinical Nurse Researcher. 10, 3, 314-331. doi: 10.1177/c10n3r7

Macneil CA, Hasty MK, Conus P et al (2010) Termination of therapy: what can clinicians do to maximise gains? Acta Neuropsychiatrica, 22, 43-45. doi: 10.1111/j.1601-5215.2009.00443.x

Mann J (1973) Time-limited Psychotherapy. Harvard University Press, London.

McCormack B, McCance T (2017) Person-Centred Practice in Nursing and Health Care: Theory and Practice. Second edition. Wiley-Blackwell, Chichester.

McCarthy, B. (2011) Hearing the person with dementia : person-centred approaches to communication for families and caregivers . London: Jessica Kingsley.

McKeown M, Wright K, Mercer D (2017) Care planning: a neoliberal three card trick. Journal of Psychiatric and Mental Health Nursing. 24, 6, 451-460. doi: 10.1111/jpm.12356

Moreno-Poyato AR, Rodríguez-Nogueira Ó (2020) The association between empathy and the nurse-patient therapeutic relationship in mental health units: a cross-sectional study. Journal of Psychiatric and Mental Health Nursing. doi: 10.1111/jpm.12675 
Moreno-Poyato AR, Casanova-Garrigos G, Roldán-Merino JF et al (2021) Examining the association between evidence-based practice and the nurse-patient therapeutic relationship in mental health units: a crosssectional study. Journal of Advanced Nursing. 77, 4, 1762-1771. doi: 10.1111/jan.14715

Morgan S (1996) Helping Relationships in Mental Health. Nelson Thornes, Cheltenham.

Nursing and Midwifery Council (2018a) The Code: Professional Standards of Practice and Behaviour for Nurses, Midwives and Nursing Associates. NMC, London.

Nursing and Midwifery Council (2018b) Future Nurse: Standards of Proficiency for Registered Nurses. NMC, London.

Oliver D (2017) David Oliver: Choosing to be honest about patient choice. BMJ. 357, j1829. doi:

10.1136/bmj.j1829

Peplau HE (1952) Interpersonal Relations in Nursing: A Conceptual Frame of Reference for Psychodynamic Nursing. G. P. Putman's Sons, New York NY.

Peplau HE (1988) Interpersonal Relations in Nursing: A Conceptual Frame of Reference for Psychodynamic Nursing. Second edition. Macmillan Education, Basingstoke.

Peterson C, Seligman ME (2004) Character Strengths and Virtues: A Handbook for Classification. Oxford University Press, Oxford.

Petronio-Coia, B. J. and Schwartz-Barcott, D. (2020) 'A description of approachable nurses: An exploratory study, the voice of the hospitalized child', Journal of pediatric nursing, 54, pp. 18-23. doi:

10.1016/j.pedn.2020.05.011.

Price B (2019) Delivering Person-Centred Care in Nursing. SAGE, London.

Rippon S, Hopkins T (2015) Head, Hands and Heart: Asset-Based Approaches in Health Care. A Review of the Conceptual Evidence and Case Studies of Asset-Based Approaches in Health, Care and Wellbeing. health.org.uk/publications/head-hands-and-heart-asset-based-approaches-in-health-care (Last accessed: 4 May 2021.)

Rogers CR (1961) On Becoming a Person: A Therapist's View of Psychotherapy. Houghton Mifflin, Boston MA. Rowan J, Jacobs M (2002) The Therapist's Use of Self. Open University Press, Buckingham.

Ryan P, Morgan S (2004) Assertive Outreach: A Strengths Approach to Policy and Practice. Churchill Livingstone, Edinburgh.

Ryle A (1995) Cognitive Analytic Therapy: Developments in Theory and Practice. John Wiley \& Sons, Chichester.

Schön DA (1983) The Reflective Practitioner: How Professionals Think in Action. Temple Smith, London.

Skourteli MC, Lennie C (2011) The therapeutic relationship from an attachment theory perspective. Counselling Psychology Review, 26, 1, 20-33.

Travelbee J (1971) Interpersonal Aspects of Nursing. Second edition. FA Davies, Philadelphia PA.

Unhjem JV, Vatne S, Hem MH (2018) Transforming nurse-patient relationships - A qualitative study of nurse self-disclosure in mental health care. Journal of Clinical Nursing. 27, 5-6, e798-e807. doi: 10.1111/jocn.14191

Wright $\mathrm{K}$, Jones $\mathrm{F}$ (2012) Therapeutic alliances in people with borderline personality disorder. Mental Health Practice. 16, 2, 31-35. doi: 10.7748/mhp2012.10.16.2.31.c9343 
Wright KM (2010) Therapeutic relationship: developing a new understanding for nurses and care workers within an eating disorder unit. International Journal of Mental Health Nursing. 19, 3, 154-161. doi: 10.1111/j.1447-0349.2009.00657.x

Wright, K.M. and Hacking S. (2011) An angel on my shoulder- the lived experience of the therapeutic relationship between women with an eating disorder and their workers. Journal of Psychiatric and Mental Health Nursing. 19 (2):107-15.

Wright, Karen Margaret (2015) Maternalism: a healthy alliance for recovery and transition in eating disorder services. Journal of Psychiatric and Mental Health Nursing, 22 (6). pp. 431439. ISSN 13510126

Wright KM, McKeown M (2018) Essentials of Mental Health Nursing. SAGE, London.

Yalom ID (1980) Existential Psychotherapy. Basic Books, New York NY. 